Article

\title{
Quantitative determination of EPA and DHA in fish oil capsules for cardiovascular disease therapy in Indonesia by GC-MS
}

\author{
Amelia Lorensia, ${ }^{1}$ Ryanto Budiono, ${ }^{1}$ Rivan Virlando Suryadinata, ${ }^{2}$ Navy Tiarasari ${ }^{3}$ \\ ${ }^{1}$ Department of Clinical Pharmacy-Community, Faculty of Pharmacy, Universitas Surabaya, Jl. Raya \\ Kalirungkut, Surabaya; ${ }^{2}$ Department of Public Health, Faculty of Medicine, Universitas Surabaya, Jl. Raya \\ Kalirungkut, Surabaya; ${ }^{3}$ Undergraduate Student, Faculty of Pharmacy, Universitas Surabaya, Jl. Raya \\ Kalirungkut, Surabaya, Indonesia
}

\begin{abstract}
Background: The consumption of EPA (Eicosapentaenoic acid), and DHA (docosahexaenoic acid), from fish oil, in the long run, has been observed to have a positive impact on patients with coronary heart disease. Fish oil products, with so much EPA and DHA content are available, and have very variable prices. Therefore, as a therapy to be used for long-term treatment, the cost factor is to be considered.

Design and methods: This study analyzed the content of EPA and DHA, using GC-MS. The sample to be analyzed was the fish oil that has the lowest price (Product A1), and that of the highest (Product A2). Furthermore, the macroscopic analysis was performed, by observing the physical form including organoleptic and qualitative tests, by reading the fragments identified by EPA and DHA.

Results: Clinical trials were conducted on patients (about 46 people), with risk factors and dyslipidemia. Product A1 showed EPA at $t_{R}=15.574 \mathrm{~min}$ (relative $\%=88.49 \%$, similarity $=95 \%$ ), and DHA at $t_{R}=21.714 \mathrm{~min}$ (relative $\%=88.92 \%$, similarity $=93 \%$ ). Product A2 showed EPA at $t_{R}=28.719 \mathrm{~min}$ (relative $\%=22.58 \%$, similarity $=89 \%$ ), and DHA at $\mathrm{t}_{\mathrm{R}}=32.327 \mathrm{~min}$ (relative $\%=22.87 \%$, similarity $=90 \%$, which meant that both had EPA and DHA contents, in accordance with their labels. Both products were confirmed to reduce total cholesterol in 4 weeks $(p=0.000, p=0.000)$, with no significant difference in their effectiveness $(\mathrm{p}=0.652)$.

Conclusion: The results showed that both the A1 and A2 products, had the EPA and DHA contents in accordance with their respective labels. However, with the A2 product having a percentage relatively higher than that of the A1 brand, both are equally very effective.
\end{abstract}

\section{Introduction}

World Health Organization described cardiovascular disease as the top leading cause of death in the world. In 2005, an estimated number of 17 million people died of cardiovascular disease, representing $30 \%$ of the total global mortality. About $80 \%$ of these deaths occurred in low- and middle-income countries. ${ }^{1}$ In Indonesia, this condition is included in the top 10 non-communicable diseases, experienced by many people. Furthermore, cardiovascular disease often encountered by adult, is coronary heart illness and failure. ${ }^{2}$ Deaths caused by this condition, especially coronary heart disease (CHD) and stroke, keep on increasing, and predicted to reach 23.3 million mortality by $2030 .^{3}$

The biggest risk factors for CHD are, obesity and diabetes, with overweight adolescents, which increase the number of obese, by an additional $5 \%-15 \%$ in 2035 , resulting to 100,000 new cases. ${ }^{4}$ The heart obtains lipids from circulating non-esterified fatty acids (FFAs), and esterified FAs, bound to lipoprotein. The abnormal regulation of lipid uptake, or its intracellular metabolism, play an important role in heart diseases. ${ }^{5}$ This supports the theory that, there is a relationship between cholesterol level (LDL), and the risk of cardiovascular disease (CVD). ${ }^{6}$

Also, blood cholesterol is related to the amount of fat, in the composition of daily food (diet). Cholesterol-lowering diets include delicacies that are low in fat, replacing food composition with those containing unsaturated fats, or rich in omega-3.7,8 Omega-3 polyunsaturated fatty acids (n-3 PUFAs), consists of EPA (eicosapentaenoic acid) and DHA (docosahexaenoic acid) contents. It is widely contained in fish, possessing protective effects, against cardiovascular disease and hyperlipidemia. ${ }^{9,10}$ DHA and EPA are important food nutrients for human health, which are defined as essential fatty acids, because they are not synthesized by the body, and are often obtained from the diet. ${ }^{11}$ These nutrients play an important role in the human body, by reducing bad cholesterol, in a bid to prevent $\mathrm{CHD},{ }^{12,13}$ through pleiotropic effects on cell function, which does affect blood lipids, inflammation, with endothelial cell and cardiomyocyte roles. ${ }^{14}$

EPA and DHA consumption in the long run, has been observed to have a positive effect on patients with $\mathrm{CHD}$, to reduce the risk of sudden death. ${ }^{15}$ Intake of fish oil containing EPA and DHA $1 \mathrm{~g} /$ day, has been widely recommended for CHD patients. However, intake in excess of $3 \mathrm{~g} /$ day is also not recommended, because it can reduce immune system function, as it lowers body inflammatory responses, and increases bleeding time due to high dosage. ${ }^{16}$

Significance for public health

Omega-3 consists of EPA and DPA, that provides significant benefits in lowering total cholesterol, which also, reduces the risk of cardiovascular disease. The omega-3 products in the market have relative percentage variability that affects the purification formulas of EPA and DHA, which often cause very large price variations. Furthermore, it is necessary to identify, whether the price difference also affects its effectiveness. 
Fish oil products that have so much EPA and DHA contents, are available, and have very variable prices. Furthermore, as a therapy to be used for long-term treatment, the cost factor is to be considered, because it is related to compliance, ${ }^{17}$ economic burden, ${ }^{18}$ and quality of life. ${ }^{19}$ Therefore, in this study, quality control needs to be conducted, in the form of a qualitative test, to see the suitability of the EPA and DHA contents on the label.

The profiles of the chemical compounds are to be identified by using GC-MS chromatography method. The GC-MS method, used in fish oil analysis for the determination of EPA and DHA, has been confirmed to be effective and accurate..$^{20,21}$ Also, EPA and DHA are to be analyzed, by using High Performance Liquid Chromatography (HPLC), and Liquid Chromatography Mass Spectrometry (LC-MS), with the HPLC not as sensitive enough like the GC-MS, while requiring very high costs when using LCMS. ${ }^{20}$ Also, clinical trials are to be conducted, in comparing the two products, to observe the effects of EPA and DHA, in the reduction of blood cholesterol levels (LDL, total cholesterol, and triglycerides). Therefore, the aim of this study is to determine the composition of EPA and DHA in fish oil products, for cardiovascular disease treatment, using GC-MS (Gas ChromatographyMass Spectrometry).

\section{Design and Methods}

\section{Study design}

This study analyzed the contents of EPA and DHA from two fish oil products, for cardiovascular disease therapy in Indonesia, through qualitative analysis, using GC-MS, in April to December 2017. The sample to be investigated, was the fish oil that had the lowest price (Product A1, Batch Number, 604683 and Exp.Date, January 2019), and the highest rate (Product A2, Batch Number, OCT16AO1 and Exp.Date, February 2019). The study was conducted in a quantitative analysis chemistry laboratory, at the Faculty of Pharmacy, University of Surabaya, Indonesia.

\section{Chemicals and equipment}

The chemicals used in this study included n-hexane p.a, saturated sodium chloride p.a, potassium hydroxide p.a, methanol p.a, boron-trifluoride $\left(\mathrm{BF}_{3}\right)$, and distilled water. The equipment used in this study included beaker glass, measuring cup, closed test tube, 5 $\mathrm{ml} / \mathrm{cc}$ injection syringe, vials, membrane filter, millipore holder, Shimadzu QP-2010 SE brand GC-MS, Japan-using capillary column RTX-5SM (60 m x $0.25 \mathrm{~mm}$, layer thickness $0.25 \mu \mathrm{m}$ ), with minimum column temperature of $330^{\circ} \mathrm{C}-350^{\circ} \mathrm{C}$, used for sample separation. For temperature programming, the oven was maintained at $80^{\circ} \mathrm{C}$ for one min, increased at intervals of $10^{\circ} \mathrm{C} / \mathrm{min}$ to $250^{\circ} \mathrm{C}$, then reduced to $8^{\circ} \mathrm{C} / \mathrm{min}$ to $280^{\circ} \mathrm{C}$, and balanced for $5 \mathrm{~min}$. Split injection was performed at a ratio of $1: 200$, as an helium carrier gas, with $1 \mu \mathrm{l}$ injection volume of $0.73 \mathrm{ml} / \mathrm{min}$ was used. The mass spectrum, was operated in electron impact mode (EI). Furthermore, other parameters included, pressure $100 \mathrm{Kpa}$, injection temperature $250^{\circ} \mathrm{C}$, ion source EI $200^{\circ} \mathrm{C}$, interface temperature $220^{\circ} \mathrm{C}$, electron energy $70 \mathrm{eV}$, delay solvent $5 \mathrm{~min}$. For the qualitative analysis the full scan mode used for variously was 40$400 \mathrm{~m} / \mathrm{z}$ (Figure 1).

\section{Qualitative test}

Qualitative tests carried out included, organoleptic observation (visual conditions based on shape, smell, taste, and color), and sample making. A $3 \mathrm{ml}$ fish oil in soft capsules, was obtained, and placed into a centrifuge tube, with $3 \mathrm{ml}$ of potassium hydroxide methanol $(0.5 \mathrm{M})$ solution added to it. The solution was mixed together vigorously, until it became homogeneous, then heated in a $60^{\circ} \mathrm{C}$ water bath, hydrolyzed with nitrogen gas flow, while being stirred three times, for $20 \mathrm{~min}$. Furthermore, $3 \mathrm{ml}$ of $\mathrm{BF}_{3}$ was added, after which the solution was cooled. The solution was heated at $60^{\circ} \mathrm{C}$ of water bath, and hydrolyzed again with nitrogen gas, for $5 \mathrm{~min}$. Saturated sodium chloride solution of $2 \mathrm{ml}$, and $2 \mathrm{ml} \mathrm{n}$ hexane were added, mixed vigorously and centrifuged at 4000 $\mathrm{rpm}$, for $10 \mathrm{~min}$. Supernatant was also obtained for use, as a sample solution. An aliquot of $1 \mu \mathrm{l}$ supernatant, was then injected for GC-MS analysis (Figure 2).

\section{Clinical trials}

The clinical trials in humans used the randomized controlled trial (RCT) method. The research subjects were adults aged $>18$ year-old, and dyslipidemic patients having $\geq 1$ of CVD risk factors, with CHD uncertainty. The assessment of CVD risk factors in the next 10 years are conducted, using the Framingham risk score. ${ }^{22}$ This includes body mass index (BMI), blood pressure, smokers, physical activity, and increased blood sugar. ${ }^{23-25}$ The criteria for the study subjects were, no history of kidney and heart disease. The research subjects were divided into two groups namely, those that use A1 and A2 products routinely, everyday. Each group watched for 4 weeks, and consisted of 23 people, with a purposive sampling method. Further test was carried out for total cholesterol (mg/dl), using Accutrend ${ }^{\circledR}$ GCT (Figure 3).

The sample size used in this study was 23 people, taking into account the value of $Z=1.96$ and $p=0.015$, which is the proportion for certain properties, estimated from Indonesian Heart Association (2017). ${ }^{26}$

\section{Results and Discussions}

\section{Identification of omega 3 in fish oil}

The organoleptic observations of product $\mathrm{A} 1$ and $\mathrm{A} 2$ included, shape, color, odor, and taste. The results showed that, both products have the same form (oil), color (clear yellow), smell (fishy), and taste (like fish). The results of the study by GC-MS, obtained

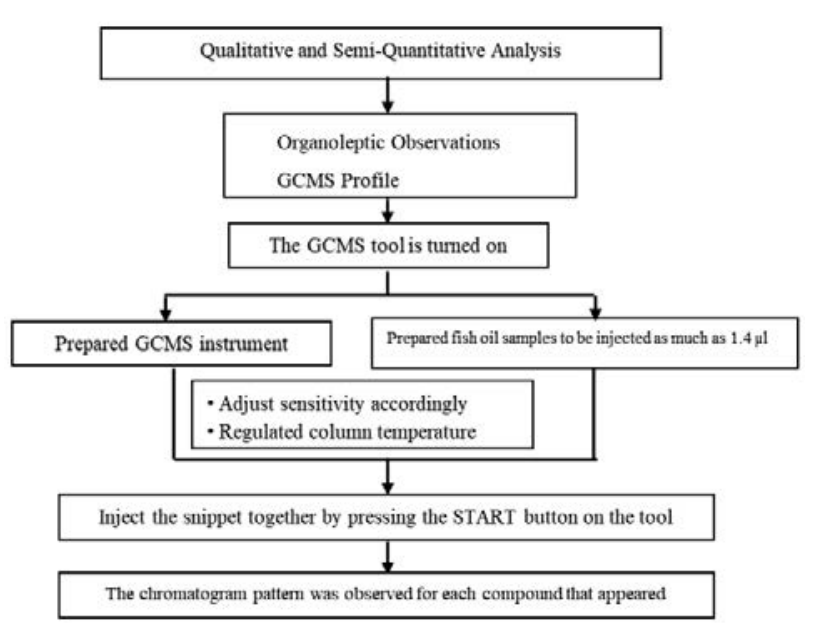

Figure 1. EPA and DHA test scheme on fish oil with GCMS. 


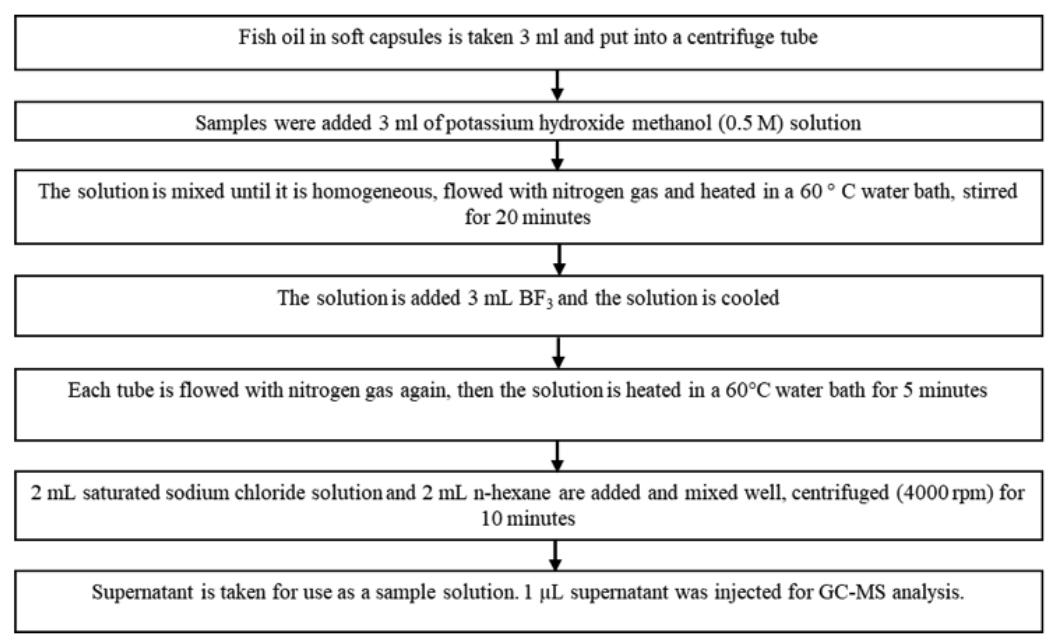

Figure 2. Work scheme preparation of fish oil samples.

two chromatograms and mass spectra, which were derived as products from the analysis. The identification of fish oil using Gas Chromatography-Mass Spectroscopy (GC-MS), showed 49 peaks on the chromatogram profile shown in Figure 4, with the highest observed at 28 and 32 . The mass spectrum of the compound at

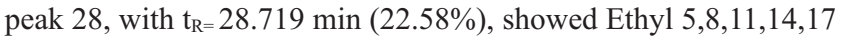
Eicosapentaenoate (Figure 5a). Based on data from the NIST08.LIB library, Ethyl 5,8,11,14,17 Eicosapentaenoate has the molecular formula $\mathrm{C}_{21} \mathrm{H}_{32} \mathrm{O}_{2}$, with a molecular weight of 316 , and a basic peak at $\mathrm{m} / \mathrm{z} 79$. The structure shown is clearly the same as that of the EPA in Figure 5a, with $89 \%$ similarity.

The mass spectrum of the compound at peak 32 with $t_{R=}$ 32.327min (22.88\%), showed 4,7,10,13,16,19 Docosahexaenoic acid methyl ester, as shown in Figure $5 \mathrm{~b}$. Based on data from the NIST08.LIB library, 4,7,10,13,16,19 Docosahexaenoic acid methyl ester, has a molecular formula $\mathrm{C}_{23} \mathrm{H}_{34} \mathrm{O}_{2}$, with a molecular weight of 342 , and a base peak at $\mathrm{m} / \mathrm{z} 79$. The structure that shown is clearly observed in the appendix, equal to that of the DHA, as shown in Figure 5b, with 90\% similarity (Figure 5b).

Identification of fish oil using Gas Chromatography-Mass Spectroscopy (GC-MS), showed 50 peaks on the chromatogram profile shown in Figure 6, with the highest observed at 4 and 22, respectively (Figure 6). The mass spectrum of the compound, at peak 4 with $t_{R}=15.574$ min $(88.49 \%)$, showed Ethyl 5,8,11,14,17 Eicosapentaenoate (Figure 7a). Based on data from the NIST08.LIB library, Ethyl 5,8,11,14,17 Eicosapentaenoate has the molecular formula $\mathrm{C}_{21} \mathrm{H}_{32} \mathrm{O}_{2}$, with a molecular weight of 316 , and a basic peak at $\mathrm{m} / \mathrm{z} 79$. The structure shown is more clearly the same as that of the EPA in Figure 7a, with 95\% similarity.

The mass spectrum of the compound at peak 32 with $t_{R=}$ 32.327mins (22.88\%), showed 4,7,10,13,16,19 Docosahexaenoic acid methyl ester, as shown in Figure $5 \mathrm{~b}$. Based on data from the NIST08.LIB library, 4,7,10,13,16,19 Docosahexaenoic acid methyl ester, has a molecular formula $\mathrm{C}_{23} \mathrm{H}_{34} \mathrm{O}_{2}$, with a molecular weight of 342, and a base peak at $\mathrm{m} / \mathrm{z} 79$. The structure shown is more clearly observed in appendix, equal to that of the DHA in Figure 5b, with 93\% similarity (Figure 7b).

\section{Data analysis}

The calculations to determine the level of compounds contained in a sample, is conducted, using the equation, \%relative= (area $\div$ area total) $\times 100 \%$ (Table 1 ). The product A1, with the lowest price after being identified using GC-MS, showed EPA at $t_{\mathrm{R}=}$

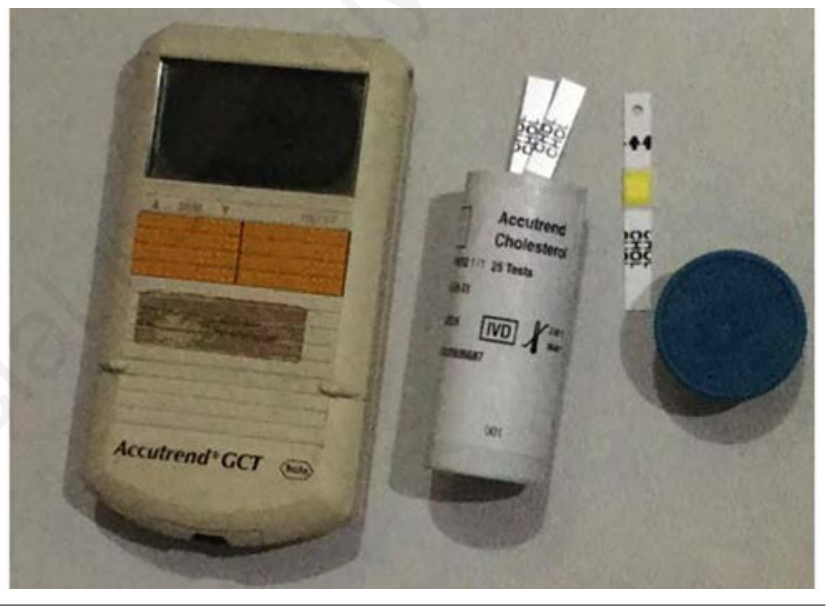

Figure 3. Cholesterol measurement tool.

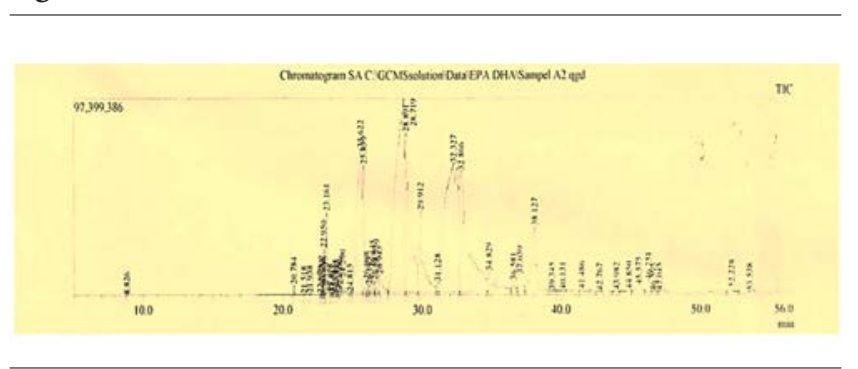

Figure 4. Chromatography profile of Product A1.

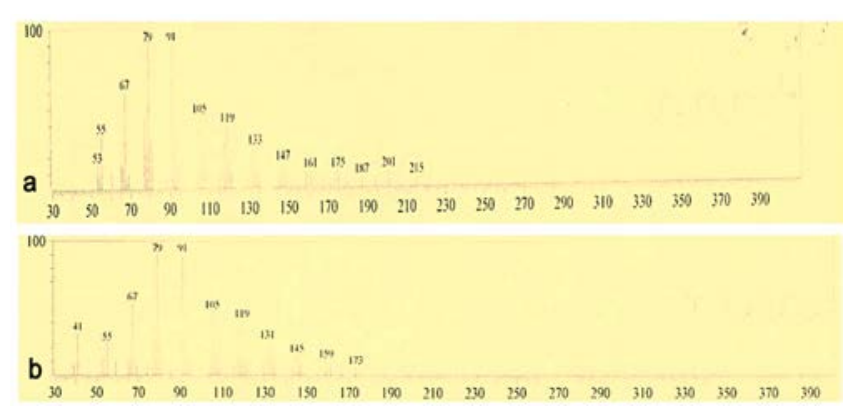

Figure 5. a) EPA peak mass spectrum highest area. b) DHA mass spectrum peaks the highest area of sample A1. 
28.719 mins, with relative $\%=22.58 \%$, having a similarity of $89 \%$, and DHA at $\mathrm{t}_{\mathrm{R}}=32,327 \mathrm{mins}$, with relative $\%=22.87 \%$, possessing a $90 \%$ similarity, which means that both contents are compatible with the label (Figure 8a). Furthermore, product A2, with the highest price, showed EPA at $t_{R}=15.574 \mathrm{~min}$, with relative $\%=88.49 \%$, having a $95 \%$ similarity, and DHA at $\mathrm{t}_{\mathrm{R}}=21.714 \mathrm{~min}$, with relative $\%=88.92 \%$, possessing a $93 \%$ similarity, which means that both contents are also compatible with the label (Figure 8b).

\section{Product effectiveness data}

Based on the characteristics shown by the respondents, majority were women, with an average age, early adult, and are students. The average pre-post total cholesterol in both product group, is above the normal average value $(<200 \mathrm{mg} / \mathrm{dl})$ (Table 2). Based on Table 3 , both product groups showed changes in pre $(p=0.000)$, and post $(\mathrm{p}=0.000)$, meaning they are equally effective in reducing total cholesterol in the blood. However, the two products showed no difference in their effectiveness, when reducing total cholesterol $(\mathrm{p}=0.652)$.

The study showed that $3 \mathrm{ml}$ of fish oil in soft capsule, was inserted into a centrifuge tube. The sample mixed with $3 \mathrm{ml}$ of $\mathrm{KOH}$, was useful for hydrolyzing into esters, or called derivatization. Both EPA and DHA which were then heated in $60^{\circ} \mathrm{C}$ water, completely hydrolyzed and flowed with nitrogen gas, to avoid being oxidized, and stirred three times for $20 \mathrm{~min}$. The fish oil was known to have a high vapor point, because the constituent substance was triacylglycerol. Therefore, before being analyzed by GC-MS, the methyl ester form was changed, using methanol and Boron trifluoride $\left(\mathrm{BF}_{3}\right)$ as a catalyst. This form of fatty acid methyl ester, was then injected into the GC-MS device. $\mathrm{BF}_{3}$ was added to the sample, and the solution was cooled.

BF3 bind well to atoms with high electronegativity, to form complexes. The solution was heated over a $60^{\circ} \mathrm{C}$ water bath for 5 mins. Saturated sodium chloride solution of $2 \mathrm{ml}$ and $2 \mathrm{ml} \mathrm{n}$ hexane were added together, mixed vigorously, and centrifuged (4000 rpm) for $10 \mathrm{~min}$. N-hexane is a solvent that was used, because of its low boiling point, lightness in removing the oil contained, and volatility in making extraction easy. Saturated $\mathrm{NaCl}$ was added to reach salting in the centrifuge, with n-hexane dissolved phase injected into GC-MS, as much as $1 \mu \mathrm{l}$.

The results of the test with GC-MS, obtained two chro-

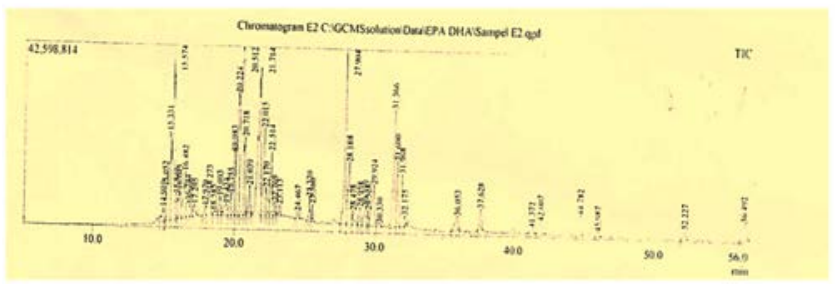

Figure 6. Chromatography profile of Product A2.

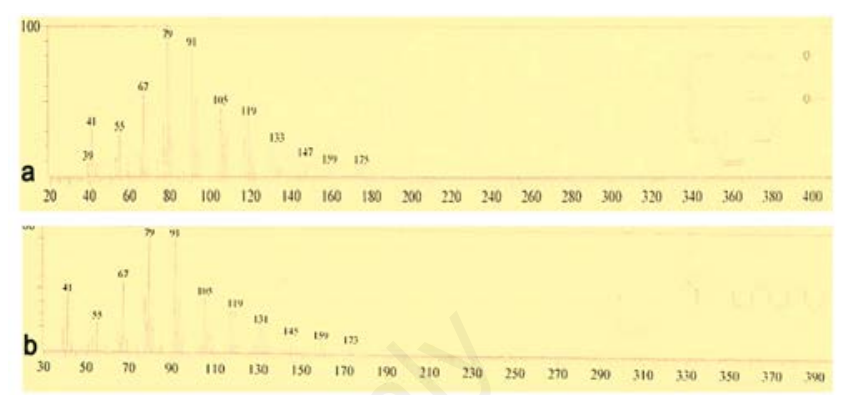

Figure 7. a) EPA peak mass spectrum highest area. b) DHA mass spectrum peaks the highest area of sample A2.
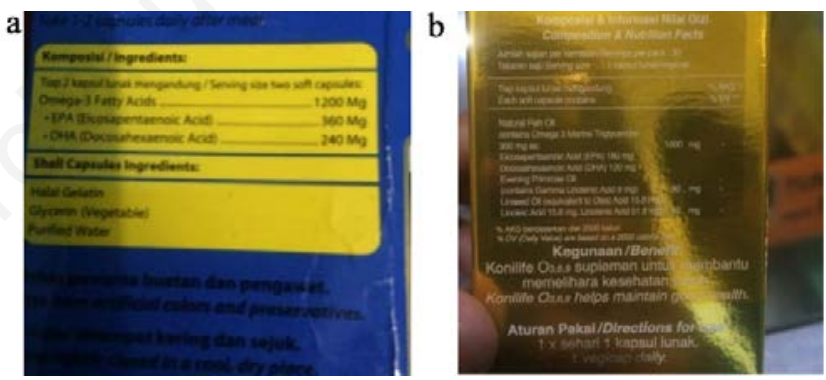

Figure 8. a) Label of Product A1 (1200 mg: $360 \mathrm{EPA}$ and 240 DHA). b) Label of Product A2 (1000 mg: $180 \mathrm{EPA}$ and 120 DHA).

Table 1. Comparison of EPA and DHA in Product A1 and A2.

\begin{tabular}{lccccc}
\multicolumn{1}{c}{ Components } & Product A1 & & & Product A2 & Area \% Relative \\
Ethyl 5,8,11,14,17 Eicosapentaenoate & 4073005037 & $22.58 \%$ & Ethyl 5,8,11,14,17 Icosapentaenoate & 449971252 & $88.49 \%$ \\
4,7,10,13,16,19 Docosahexaenoic acid, methyl ester & 4124358876 & $22.87 \%$ & $4,7,10,13,16,19$ Docosahexaenoic acid, methyl ester & 451560536 & $88.92 \%$ \\
\hline
\end{tabular}

Table 2. Characteristics of respondents.

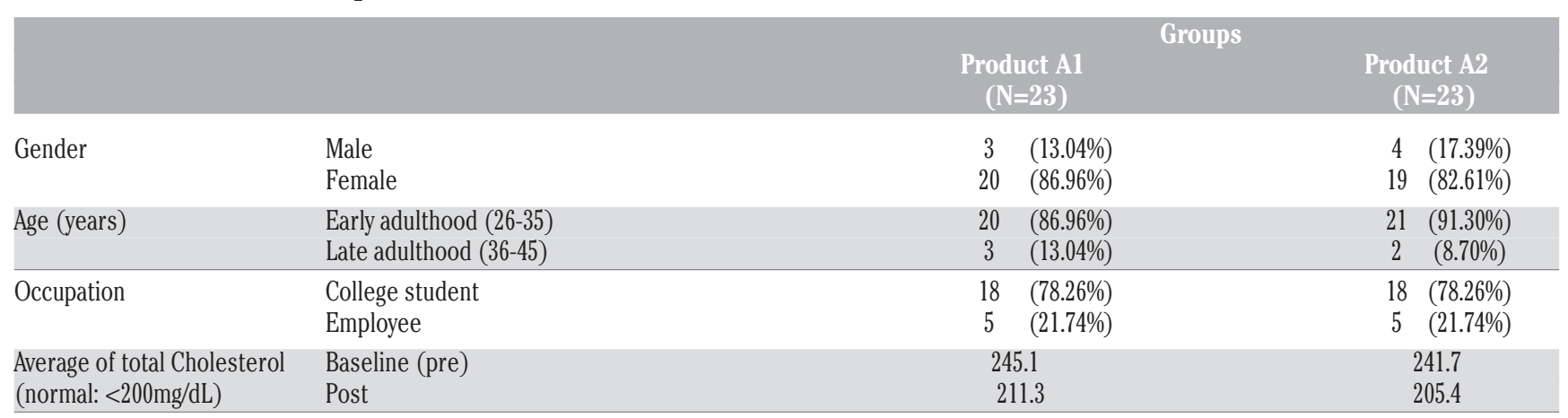


Table 3. Measurement of total cholesterol profile

\begin{tabular}{lccccc} 
Groups & $\begin{array}{c}\text { Changes in the value of total cholestero } \\
\text { Increase }\end{array}$ & $\begin{array}{c}\text { Fixed } \\
\text { Decrease }\end{array}$ & $\begin{array}{c}\text { p-value } \\
\text { (pre-post) }\end{array}$ & $\begin{array}{c}\text { p-value } \\
\text { (post A1 vs Post A2) }\end{array}$ \\
Product A1 (n:23) & 1 & 4 & 18 & 0.000 & 0.652 \\
Product A2 (n:23) & 0 & 4 & 19 & 0.000 & \\
\hline p $<0.05$ means that there are significant differences. & & &
\end{tabular}

$\mathrm{p}<0.05$ means that there are significant differences.

matograms, for gas chromatography (GC), and mass spectra, for that of mass spectroscopy (MS) analysis, functioning as $\mathrm{x}$-axis (intensity) and $\mathrm{y}$-axis (mass per charge $(\mathrm{m} / \mathrm{z})$ ), respectively. The results showed that, both the A1 and A2 products had the EPA and DHA contents, in accordance with their respective labels. Furthermore, the A2 product has a relatively higher percentage than the A1 brand, which then shows that the compound content, contained in the A2 sample is very high. Therefore, it can be concluded that, there is a relationship between price and both product contents, as observed from the relative percentage. Product A1 (with the lowest price), has relatively lower percentage, compared to brand A2 (with the highest price), which has relatively higher grade, although the dosage stated on the label of A1, is higher than that of A2. The result in Table 3, showed that the two therapy groups were equally effective at lowering total cholesterol, and there was no significant difference in effectiveness. Also, gender did not affect the risk of dyslipidemia. ${ }^{27}$ Furthermore, race factors affected the treatment of dyslipidemia more. Also, the result of the study explained that hyperlipidemia is more aggressively treated and controlled in white men, than in white women. However, black women are at the highest risk of CHD, than others. ${ }^{28}$ The age and educational level also affects dyslipidemia treatments, with the most at risk in the 50-59 years-old group. Dyslipidemia, is mostly served by patients with low levels of education. ${ }^{29}$

The sytematic review by Nejad and Bikdeli, ${ }^{30}$ in an early study, showed that supplementation with $1 \mathrm{~g}$ of omega-3 per day, significantly reduced mortality. A double-blind randomized in France, showed that, in 633 patients taking $600 \mathrm{mg}$ of omega-3 daily, for an average of 4.7 years, did not find significant decrease in major cardiovascular events. The same is the case with other studies in Netherlands, with randomized double-blind placebo-controlled trials, showing that, in 1,192 CVD patients using supplements with an average of $226 \mathrm{mg}$ EPA, and $150 \mathrm{mg}$ DHA per day, did not show significant decrease in major cardiovascular events. While another study in Germany, found no additional benefit from $1 \mathrm{~g}$ of omega-3 per day, for one year, against sudden cardiac death, and other cardiovascular events. This study had limitations, which is, not being able to know how significant the relative percentage difference is. Therefore, it is recommended for further research to determine the levels of product contents in a fish oil product, with a comparison of pure EPA and DHA. Furthermore, research is also needed to observe cost-effective events between the cost of drugs, with effectiveness in reducing cholesterol levels. Also, factors of race and occupation/education, related to health affects the risk of dyslipidemia, and adherence to medication. Further research is also needed, to compare natural resources with supplements. Omega-3 sources are more recommended in the form of food intake from fish, rather than in the form of supplements. ${ }^{31}$ Also, to lower cholesterol in the blood, omega-3s reduces blood pressure, ${ }^{32}$ with further research needed, to observe changes in the system. Also, future clinical trials need to pay attention to genetic related factors including, apoliprotein AI (apoA-I), ATPbinding cassette transporter A1 (ABCA1), ABCG1, apoE, scavenger receptor class B type I (SR-BI), cholesteryl ester transfer protein (CETP), low-density lipoprotein receptor (LDLr), cholesterol 7 alpha-hydroxylase (CYP7A1), and ABCG5/G8. ${ }^{33}$

\section{Conclusions}

The results showed that both the A1 and A2 products had the EPA and DHA contents in accordance with their respective labels. Also, with the $\mathrm{A} 2$ product having a relatively higher percentage than the A1 brand, it is shown that the compound content in the A2 sample, is high. Therefore, it can be concluded that, there is a relationship between price with, EPA and DHA content, as observed from relative percentage. Product A1 (with the lowest price), has relatively lower percentage, compared to brand A2 (with the highest price), with relatively higher grade. Therefore, both products are confirmed to reduce total cholesterol in 4 weeks, with no significant difference in their effectiveness.

Correspondence: Amelia Lorensia, Department of ClinicalCommunity Pharmacy, Faculty of Pharmacy, Universitas Surabaya (UBAYA) Jl. Raya Kalirungkut Surabaya 60293, Indonesia. Tel.+62.312981110 - Fax: +62.312981111.

E- mail: amelia.lorensia@staff.ubaya.ac.id

Key words: EPA; DHA; fish oil; cardiovascular disease; GC-MS

Contributions: The authors contributed to the research equally.

Conflict of interests: The authors declared no conflict of interest.

Funding: Research funding was provided by Faculty of Pharmacy, in the University of Surabaya. Support was also provided by Institute of Research and Community Service at the University of Surabaya, with more funding from Ministry of Research, Technology, and Higher Education of the Republic of Indonesia.

Acknowledgements: The authors are grateful to the University lecturers for their friendly support.

Ethical Approval: This study has been approved by Health Research Ethics Committee of the University of Surabaya, Indonesia, with certificate No. 004/KE/I/2017.

Conference presentation: Part of this study was presented at the $1^{\text {st }}$ International Nursing and Health Sciences Symposium, November $13^{\text {th }}$ to $15^{\text {th }} 2020$, Brawijaya University, Malang, Indonesia.

Received for publication: 14 January 2021. Accepted for publication:15 March 2021.

oCopyright: the Author(s), 2021

Licensee PAGEPress, Italy

Journal of Public Health Research 2021;10:2159

doi:10.4081/jphr.2021.2159

This work is licensed under a Creative Commons Attribution NonCommercial 4.0 License (CC BY-NC 4.0). 


\section{References}

1. Word Health Organization. Cardiovascular Disease. Geneva: Word Health Organization; 2019.

2. Ministry of Health Republic of Indonesia. Riset Kesehatan Dasar (RISKESDAS) 2013 (Basic Health Research 2013)].[in Indonesian]. Jakarta: Ministry of Health Republic of Indonesia; 2013.

3. Center for Data and Information of the Ministry of Health of the Republic of Indonesia. [Situasi Kesehatan Jantung (Heart health situation)].[in Indonesian]. Jakarta: Ministry of Health Republic of Indonesia; 2014.

4. Kones R. Primary prevention of coronary heart disease: integration of new data, evolving views, revised goals, and role of rosuvastatin in management: A comprehensive survey. Drug Des Dev Ther 2011;5:325-80.

5. Goldberg IJ, Trent C, Schulze PC. Lipid metabolism and toxicity in the heart. Cell Metab 2012;15:805-12.

6. Mathes P, Thiery J. The role of lipid metabolism in the prevention of coronary heart disease. Z Kardiol 2005;94:43-55.

7. Hayes J, Benson G. What the latest evidence tells us about fat and cardiovascular health. Diabetes Spectr 2016;29:171-5.

8. Siri-Tarino PW, Chiu S, Bergeron N, et al. Saturated fats versus polyunsaturated fats versus carbohydrates for cardiovascular disease prevention and treatment. Annu Rev Nutr 2015;35:517-43.

9. Calvo MJ, Martinez MS, Torres W, et al. Omega-3 polyunsaturated fatty acids and cardiovascular health: a molecular view into structure and function. Vessel Plus 2017;1:116-28.

10. Veno SK, Bork CS, Jakobsen MU, et al. Marine n-3 polyunsaturated fatty acids and the risk of ischemic stroke. Stroke 2019;50:274-82.

11. Fournier V, Juanéda P, Destaillats F, et al. Analysis of eicosapentaenoic and docosahexaenoic acid geometrical isomers formed during fish oil deodorization. J Chromatogr A 2006;1129:21-8.

12. Abdelhamid AS, Martin N, Bridges C, et al. Polyunsaturated fatty acids for the primary and secondary prevention of cardiovascular disease. Cochrane Database Syst Rev 2018;7:CD012345.

13. Khandelwal S, Kelly L, Malik R, et al. Impact of omega-6 fatty acids on cardiovascular outcomes: A review. Preventive Cardiol 2013;2:325-36.

14. Jump DB, Depner CM, Tripathy S. Omega-3 fatty acid supplementation and cardiovascular disease. J Lipid Res 2012;53:2525-45.

15. Swanson D, Block R, Mousa SA. Omega-3 fatty acids EPA and DHA: health benefits throughout life. Adv Nutr 2012;3:17.

16. Bradberry JC, Hilleman DE. Overview of omega-3 fatty acid therapies. PT 2013;38:681-91.

17. Osamor PE, Owumo BE. Factors associated with treatment compliance in hypertension in Southwest Nigeria. J Health Popul Nutr 2011;29:619-28.

18. Tarride JE, Lim M, Meules MD, et al. A review of the cost of cardiovascular disease. Can J Cardiol 2009;25:e195-202.

19. Ko HY, Lee JK, Shin JY, et al. Health-related quality of life and cardiovascular disease risk in Korean adults. Korean $\mathrm{J}$ Fam Med 2015;36:349-56.

20. Yi T, Li SM, Fan JY, et al. Comparative analysis of EPA and DHA in fish oil nutritional capsules by GC-MS. Lipids Health Dis 2014;13:1-6.

21. Bratu A, Mihalache M, Hanganu A, et al. Quantitative determination of fatty acids from fish oils using GC-MS method and H-NMR spectroscopy. UPB Sci Bull B 2013;75:23-32.

22. Medscape [Internet]. Framingham 10 year risk of general cardiovascular disease (2008) [updated 2020 Nov; cited 2020 Nov 10]. Available from: Available from: https://reference.medscape.com/calculator/framingham-cardiovascular-disease-risk

23. Hajar R. Risk factors for coronary artery disease: Historical perspectives. Heart Views 2017;18:109-14.

24. So JH, Lee JK, Shin JY, et al. Risk of cardiovascular disease using Framingham risk score in Korean cancer survivors. Korean J Fam Med 2016;37:235-41.

25. D'Agostino RB, Pencina MJ, Massaro JM, et al. Cardiovascular disease risk assessment: Insights from Framingham. Global Heart 2013;8:11-23.

26. Indonesian Association of Cardiovascular Specialists. Panduan Tata Laksana Dislipidemia 2017 (Guidelines for Dyslipidemia Management 2017)].[in Indonesian]. Available from: http://www.inaheart.org/upload/image/lipid.pdf

27. Peters SAE, Munther P, Woodward M. Sex differences in the prevalence of, and trends in, cardiovascular risk factors, treatment, and control in the United States, 2001 to 2016. Circulation 2019;139:1025-35.

28. Safford MM, Gamboa CM, Durant RW, et al. Race-sex differences in the management of hyperlipidemia. Am J Prev Med 2015;48:520-7.

29. Cho SMJ, Lee HJ, Shim JS, et al. Associations between age and dyslipidemia are differed by education level: The Cardiovascular and Metabolic Diseases Etiology Research Center (CMERC) cohort. Lipids Health Dis 2020;19):1-12.

30. Nejad AM, Bikdeli B. Omega-3 supplements and cardiovascular disease. Tanaffos 2014;13:6-14.

31. Zibaeenezhad MJ, Ghavipisheh M, Attar A, et al. Comparison of the effect of omega-3 supplements and fresh fish on lipid profile: a randomized, open-labeled trial. Nutr Diabetes 2017;7:1-8.

32. Colussi G, Catena C, Novello M, et al. Impact of omega-3 polyunsaturated fatty acids on vascular function and blood pressure: Relevance for cardiovascular outcomes. Nutr Metab Cardiovasc Dis 2017;27:191-200.

33. Pizzini A, Lunger L, Demetz E, et al. The role of omega-3 fatty acids in reverse cholesterol transport: A review. Nutrients 2017;9:1-12. 